\title{
Monash editorial
}

\author{
Jonathan Ives ${ }^{1} \cdot$ Veerle Provoost ${ }^{2}$
}

This editorial begins, perhaps unusually, with a personal anecdote from Ives, one of the editors of this special edition, which sets the scene for the edition and, to some extent, explains why the debates presented in these pages are needed:

When I was first starting out as a Ph.D. student in 2004, I submitted a paper to a philosophy journal that discussed the ethics of creating fatherless families. The paper tried to unpick the debate, sort out the moral claims from the empirical ones, and consider how implicit value claims affected the way that the empirical data were used in 'ethical' argument. As such, a good deal of the paper was devoted to critically assessing various key pieces of empirical evidence, which made claims either that children were harmed by being without a father, or that they were not. The paper was not accepted for publication (and most probably for good reason), but I was struck by one comment from a reviewer, who asked what business I had looking critically at research evidence, and why on earth did I think I had the skills to do so? What I should do as an ethicist, I was implicitly told, is cite the evidence and be done with it.

Jonathan Ives

j.c.ives@bham.ac.uk

Veerle Provoost

veerle@provoost.org

1 MESH, School of Health and Population Science, The University of Birmingham, Edgbaston, Birmingham B15 2TT, UK

2 Department of Philosophy and Moral Sciences, Bioethics Institute Ghent, Ghent University, Blandijnberg 2, 9000 Ghent, Belgium 
This anecdote highlights one particularly polarised view about the appropriate relationship between bioethics and empirical data. The view of that reviewer was that the bioethicist ought to be a grateful and uncritical consumer of empirical evidence, and be directed in its use by those who know about those things.

To ask whether empirical data have a role to play in bioethics seems a strange question, and it is one with an obvious answer. Questions like what that role ought to be, in what varied ways can bioethics appropriately make use of it, and to what extent and level bioethics ought to engage directly with empirical data, are more interesting and perhaps more contested. Empirical data have always been used to support premises in bioethical argument, but a recent move towards 'empirical bioethics' has generated an increasing amount of debate around how to incorporate empirical data into normative theorising in ways that go beyond using empirical facts to complete a hypothetical imperative. The literature here is wide and varied, and points towards new ways of doing bioethics that challenge traditional disciplinary orthodoxies (e.g. Davies et al. 2015; Ives 2014; Dunn et al. 2012; Frith 2010; de Vries and van Leeuwen 2010; Widdershoven et al. 2009; Leget et al. 2009; Haimes and Williams 2007; Molewijk et al. 2004). One of the driving tenets of this literature is that by changing the way we 'do bioethics' we can make our theorising more relevant to policy. Not only might such bioethics be more policy friendly in that it could engage directly with the policy agenda, but it would also be more closely rooted in context and practice, and therefore more useful and relevant to the everyday difficulties and practical contingencies policy has to deal with. In this literature, the philosopher who sits and 'thinks in a special way' (Hedgecoe 2004) about ethical issues, abstracted from the real world, is replaced by an interdisciplinary researcher, who draws on the tools of normative philosophical ethics and a range of other theoretical and empirical disciplines to undertake considered, contextually aware, and policy relevant research (Ives 2014).

Whilst the theoretical debate is set to continue over the most appropriate methodologies for doing this, there is always time to pause and take a look at how this debate is being 'fleshed out' in a particular area. We can, in this respect, take a cue from de Vries et al. (2004) who, in their introduction to a Sociology of Health and Illness monograph, called for researchers to stop theorising about empirical bioethics and get on and do it, so that we can look at how it is done.

Partly with this in mind, a symposium, funded by the Brocher Foundation, was organised under the title 'On gametes and guidelines: A symposium for exploring the use of interdisciplinary and empirical bioethics to inform the regulation of reproductive technologies'. The symposium brought together European scholars working on reproductive ethics, reproductive policy, and empirical bioethics methodology, to discuss and debate the various ways in which data are, and can be, used to inform arguments around reproductive technology and the provision of assisted reproduction. This editorial introduces a special edition of the journal devoted to papers, presented at that symposium, that consider the role of empirical evidence in the ethical policy debates about gamete donation. Reproductive ethics and empirical science have long been intertwined. It is an area of ethical and policy debate where empirical evidence about efficacy and safety, as well as social scientific data about people's preferences and values, have had, and continue to 
have, a demonstrable impact; and this symposium was convened to explore perspectives on that relationship.

This special edition can be viewed from two different perspectives, depending on what the reader wants to get out of it. First, it can be viewed as a collection of papers that focus on central issues in reproductive ethics and policy surrounding gamete use, albeit with an empirical bent. Second, it can be viewed as a collection of papers that provide examples of the ways in which empirical evidence might inform a bioethical debate (related to policy in gamete donation, or in general), as well as critiques of how this has been done. As editors, it is the combination of these two perspectives that interests us.

\section{Overview}

The collection begins with a paper from Soren Holm and Thomas Ploug that offers an analysis of the different aims of policy makers and philosophers, and considers how these differences entail different needs for, and uses of, empirical data. Holm and Ploug start by looking at the topic from the perspective of policy makers, and ask what kind of empirical evidence they are looking for in the process of developing policy. They point to the messiness of the policy making process, and the influence of many factors besides the empirical evidence; such as the timing of a study and the policy makers' framing of the issue (which is often political). The authors advise bioethicists who want to increase the chance of their work being picked up by policy makers - and achieving impact - to take into account these factors, especially the policy makers' framing of the issue, and to engage with relevant networks and the media. Their conclusions about the 'messiness' of policy making, compared to the precision and consistency that is sought in philosophical analysis, and the need for both empirical and ethics research to be cognisant of the policy agenda in order to have impact, set the scene for the rest of the collection which, in various ways, provide examples and analyses of attempts to use empirical data to make normative claims more policy relevant.

The paper that follows, from Marta Spranzi and Laurence Brunet, explores an attempt by the French Government to undertake a wide ranging public consultation on the use of reproductive technology, in order to produce ethically acceptable policy. Spranzi and Brunet draw attention to the presuppositions about the role of the public that are necessary for such a consultation. They pose the question of when it is appropriate to follow citizen's recommendations and when not, and discuss the limitations of consensus conferences and other exercises in deliberative democracy (while also acknowledging other legitimate goals of such exercises, aside from gathering evidence about public views, such as informing the public and building their trust in science through participation).

Focussing on the specific issue of donor anonymity, their analysis of this consultation process highlights the challenges inherent in any attempt to introduce a deliberative democratic process into policy making, because of the tendency of such approaches towards conservatism and interpretation of data that serves to reinforce, rather than challenge, existing norms. Whilst it might be argued that some tendency 
toward conservatism could be protective, and is a price we might be willing to pay to ensure that ill thought out changes are not rushed through (Ives 2014), the analysis presented by Spranzi and Brunet highlight the way that the design of a consultation, and the people involved, can significantly impact upon the kinds of conclusions reached. This analysis challenges the relatively simplistic accounts of 'empirical data gathering' that we find in accounts like that offered by Kon (2009), which (wrongly) imply that gathering and interpreting data on stakeholder and public opinion is a straightforward activity (see also Dunn and Ives 2009). The paper broadens our perspective by pointing to what precedes and shapes the empirical phase, making it more or less difficult to gather useful and credible evidence of a particular type.

Following this is Lucy Frith's paper, which uses the UK's removal of gamete donor anonymity as a lens through which to examine, first, what counts as 'good' evidence, and then the role that empirical evidence can play in informing ethical policy. Frith starts by reviewing critically the evidence used in the removal of gamete donor anonymity in the UK in 2005 , to point to the difficulties of using empirical data in policy-making. The focus at the end of her paper turns away from empirical evidence, as such, and towards what values and principles undergird our quest for evidence; as these values and principles will not only shape the debate but also frame the empirical questions we ask and what evidence we consider relevant. In relation to the disclosure of identifying information about donors to donor conceived children, she concludes that the focus on the best interests of the child is justified by argument rather than empirical evidence.

Her analysis, ultimately, leads to the conclusion that even when we have an idea of what counts as good and relevant evidence, such evidence can only take us so far. The evidence cannot tell us which ethical principles or values should guide our decision making, which speaks to the importance of philosophical ethics retaining a central role in decision making. Data can, however, shed light on what principles and values people feel are important, which may be a good starting place for debate around policy. As such, Friths' paper is in line with her previous work (e.g. Frith 2010), where she also stresses the importance of maintaining the central role of moral theory, as it is moral theory that give an analysis its critical force.

The next paper, by Tabitha Freeman, picks up on one of the key points raised by Frith, and explores what counts as good and relevant evidence; specifically in relation to empirical evidence used in the debate around gamete donation and child well-being. One of the central premises of the paper takes Frith's point that there are some features of ethical questions that no amount of empirical evidence can resolve, and it goes on to explore the use and misuse of empirical data in this debate.

Freeman addresses a fundamental argument in the debates about gamete donation and child welfare, by exploring key empirical evidence about child wellbeing. Her paper outlines key concerns underpinning the current regulatory debates about information sharing and the best interests of the child, and in doing so unpicks three different concerns related to different forms of impact on child wellbeing: (1) impact from the gamete donation per se, (2) impact from parental disclosure decisions and (3) impact from donor identification. Freeman points to ideas about the significance of the genetic link between parents and their children as 
fundamental to understanding how questions around psychosocial impact (of the three different concerns of gamete donation she identifies) are framed. Fundamentally, the paper explores the inherent normativity (and, implicitly, the nonneutrality) of empirical research that examines child welfare, the risk of findings being 'lost in translation', and highlights some of the 'nuances and complexities' of this kind of empirical research. In doing so, she shows that importing empirical findings simplistically into ethical debate is highly problematic.

The use and misuse of empirical data in bioethics argument is picked up by Provoost in the next paper, which explores, through a critical literature review, the ways in which secondary empirical data can be, and has been, (mis)used by bioethicists in the debate on assisted reproduction. Provoost's conclusion, that bioethicists ought to pay more critical attention to the studies they use, and her reflections on standards of practice to prevent misuse (or inappropriate use) of empirical data in the bioethics literature, sets up the final paper, by Guido Pennings, which is in an example of ethical analysis (of the role of altruism in gamete donation) that draws explicitly, and deeply, on empirical evidence.

In light of the topic of this special issue, in the final paper, the way that Pennings uses empirical evidence is more interesting than his conclusion. First, the analysis presented in the paper itself was triggered by findings from an empirical study looking at oocyte donor motivations. Second, the analysis then directly draws on data about donor motivation to question what donor motivations ought to be. Pennings uses empirical data to critically study the concept of altruism as the 'core value' for gamete donation, and reflects on whether a model of solely altruistic gamete donation is realistic. He argues that, in practice, it is very difficult to make a distinction between donations that are altruistic and those that are not. The paper discusses several values that compete with altruism (beneficence, solidarity and reciprocity), and argues that these different values should be balanced, taking into account the specific context of the donation. On the practical front, drawing on empirical data, Pennings argues that it is difficult to distinguish between removing barriers and offering incentives. In this paper, empirical data is simultaneously used as springboard into an analysis, used to support factual premises made within an argument, and used to problematise the concept of 'altruism' that is being employed in donation policy. These uses of data resonate with many of the uses outlined by Provoost in the previous paper.

\section{Final remarks}

The aim of this issue (and of the symposium) was not to provide a canonical account of what relationship bioethicists ought to have with empirical data, either in terms of collecting it, analysing it, or using it. We ended up doing quite the opposite, in fact. The many different focusses and questions raised by the authors who have contributed to this special edition (and to the symposium debates) indicate that we are a long way from answering the fundamental methodological questions about empirical bioethics and its impact on, or use for, policy. If anything, the 
contributions in this issue have pointed to the need for a continued and profound reflection on these methodological questions (see also Davies et al. 2015).

This collection of papers shows, primarily, that when bioethicists enter the world of empirical bioethics, they will need to address many additional questions. These questions concern, inter alia, the values and principles underlying our empirical research questions, the way policy makers frame the debate, what type of evidence we will consider relevant and of good quality etc. This issue aims to promote further reflection and debate about how we as bioethicists conduct or interpret empirical studies, and especially about how we can and should make use of empirical data to reach normative conclusions.

Finally, we would like to thank the managing editors of this journal, and the production team, for the opportunity to compose a special issue on the topic of the symposium, as well as the authors and the peer reviewers who contributed or advised on contributions.

\section{References}

Davies, R., J. Dunn, and M. Ives. 2015. A systematic review of empirical bioethics methodologies. BMC Medical Ethics 16: 15.

de Vries, M., and E. van Leeuwen. 2010. Reflective equilibrium and empirical data: Third person moral experiences in empirical medical ethics. Bioethics 24(4): 490-498.

de Vries, R., L. Turner, K. Orfali, and C. Bosk. 2004. Social science and bioethics: The way forward. In The view from here: Bioethics and the social sciences, ed. R. de Vries, L. Turner, K. Orfali, and C. Bosk. London: Sociology of Health and Illness Monographs, Blackwell.

Dunn, M., and J. Ives. 2009. Methodology and epistemology in bioethics research: A constructive/ist commentary. American Journal of Bioethics 9(6-7): 93-95.

Dunn, M., M. Sheehan, M. Parker, and T. Hope. 2012. Toward methodological innovation in empirical ethics research. Cambridge Quarterly of Healthcare Ethics 21(4): 466-480.

Haimes, E., and R. Williams. 2007. Sociology, ethics and the priority of the particular: Learning from a case study of genetic deliberations. The British Journal of Sociology 58(3): 457-476.

Hedgecoe, A. 2004. Critical bioethics: Beyond the social science critique of applied ethics. Bioethics 18(2): 120-143.

Frith, L. 2010. Symbiotic bioethics: A practical methodology. Bioethics 26(4): 198-206.

Ives, J. 2014. A method of reflexive balancing in a pragmatic, interdisciplinary and reflexive bioethics. Bioethics 28(6): 302-312.

Kon, A. 2009. The role of empirical research in bioethics. American Journal of Bioethics 9(6-7): 59-65.

Leget, C., P. Borry, and R. de Vries. 2009. 'Nobody Tosses a Dwarf!' The relation between the empirical and the normative reexamined. Bioethics 23(4): 226-235.

Molewijk, B., A. Stiggelbout, W. Otten, H. Dupois, and J. Kievit. 2004. Empirical data and moral theory. A plea for integrated empirical ethics. Medicine, Health Care and Philosophy 7: 55-69.

Widdershoven, G., A. Tineke, and B. Molewijk. 2009. Empirical ethics as a dialogical practice. Bioethics 23(4): 236-248. 